\title{
A Long-Term perspective of Wind Power Output Variability
}

\author{
N. Kirchner-Bossi a ${ }^{\text {, R. García-Herrera*a,b }}{ }^{*}$ L. Prieto ${ }^{c}$, \\ R.M. Trigo ${ }^{\mathrm{d}}$ \\ ${ }^{a}$ Department of Physics of the Earth, Astronomy and Astrophysics II, Universidad \\ Complutense de Madrid. \\ ${ }^{\mathrm{b}} I G E O$, Instituto de Geociencias, CSIC-UCM. \\ ${ }^{\mathrm{c}}$ Department of Energy Resource, Iberdrola Renovables Energía. \\ ${ }^{\mathrm{d}}$ Istituto Dom Luiz (IDL), Faculdade de Ciências, Universidade de Lisboa.
}

\begin{abstract}
The study of the wind power output variability comprises different time scales. Among them, low-frequency variations can substantially modify the performance of a wind power plant during its lifetime. Although in recent years other scales, as the short-term variability or the climatological conditions of wind and the corresponding generated power have been investigated in depth, the study of the decadal and multidecadal variations is still placed in its early stages.

In this work the wind power output long-term variability is analyzed for two locations of wind power relevance in Spain, during the period 1871-2009. This is attained by computing the annual wind speed Probability Density Functions (PDF) from an ensemble of atmospheric Sea Level Pressure (SLP) data set from the 20th Century Reanalysis through a statistical downscaling based in Evolutionary Algorithms. Results reveal significant trends and periodicities in multidecadal bands including 13, 25 and 46 years, as well as significant differences among both sites. The impact of the leading large-scale circulation patterns (NAO, EA, SCAND and AMO) on wind power output and its stationarity is analyzed. Results on both locations show significant and opposite seasonal couplings with these forcings. Finally, the long-term variability of the reconstructed Weibull parameters of the annual wind speed distributions are employed to derive a linear model to estimate the annual wind power.
\end{abstract}

Key words: wind power, long-term variability, statistic downscaling, wind field classification, evolutionary algorithms, teleconnection patterns. 


\section{Introduction}

Interdecadal and multidecadal changes in surface wind have been evidenced in several works during the last decades (e.g., Palutikof (1985); Earl et al. (2013); Kirchner-Bossi et al. (2013)). They have been associated to the long-term changes of large scale circulation forcings (e.g., Pryor et al. (2005a); Spears and Jones (2010); García-Bustamante et al. (2012); Jerez et al. (2013); Jerez and Trigo (2013)). Since the typical life span of most wind farms is planned up to 25 years, this type of variability can have significant impact in wind power production. Specially, due to the increasing share of wind power worldwide (e.g., about $16 \%$ in 2011 with $21 \%$ of the national installed power in Spain (REE, 2012), or 35\% of net power generation in Denmark (Energinet, 2013) in 2012).

However, wind power variability at multidecadal time scales has not been traditionally taken into account in wind power facilities planning and management, due to the unavailability of representative long enough time series, or because wind industry has focused in shorter time scales. These include very short-term scales associated to the wind power forecast (1 to 72h, e.g., Marti et al. (2006); Pinson et al. (2007); Giebel et al. (2011)), or average wind values in the development of wind atlases or wind resource availability analyses derived from few years of measurements (e.g, Martner and Marwitz (1982); Archer and Jacobson (2003); Celik (2004)).

The main problem faced in the analysis of the multidecadal variability of wind power outputs is the availability of time series long enough to detect such changes. However, because of the relatively recent implementation of the wind power industry, wind power measurements usually comprise only a few years of data. Furthermore, in the case that this kind of data was considered, a number of factors might

\footnotetext{
* Corresponding author: Ricardo García-Herrera. Department of Atmospheric Sciences, Universidad Complutense de Madrid. 28040 Madrid. Spain.

Tlph: +34913945238

Fax: +34 913944635

Email address: rgarciah@fis.ucm.es (R. García-Herrera*).
} 
not be taken into account, thus distorting its relationship with the wind regime, especially if working with daily, monthly or annual scales. These issues include wake effects in relation to other wind turbines nearby (Manwell et al., 2002), unexpected shutdowns by damage, periods where wind speed values are placed beyond the operating range of the turbine (minimum or maximum, Jerez et al. (2013)), or turbine degradation factors (e.g., Reid et al. (2013); Sareen et al. (2013)). Although several works consider directly the actual measurements of power output, most of them focus on the assessment of the wind power variability in the short term (Lee and Baldick, 2012; Frehlich, 2013) or on the analysis of different operational features of wind farms (Fertig et al., 2012) or turbines (Ribrant and Bertling, 2007).

Given the infeasibility to ensure a long enough representative wind power output data set for a given point, this has been traditionally derived from wind speed by following different strategies (e.g., Lee and Baldick (2012); Jerez et al. (2013)). Thus, the wind speed PDF (Probability Density Function) can be fitted to a Weibull distribution (Weibull et al., 1951), since this function can be clearly defined by only two parameters. However, this adjustment can imply different caveats (Tuller and Brett, 1984; Jamil et al., 1995; García-Bustamante et al., 2008), so the actually measured PDF has also been considered (Brayshaw et al., 2011; Jerez and Trigo, 2013).

As is the case of wind power, quite often the evaluation of the wind speed is based on in situ measurement masts containing only a few years of data (e.g., McIntyre et al. (2011); Bayray et al. (2013). There exist different approaches to obtain longer series representative of the local conditions. Thus, data from nearby meteorological stations (Pashardes and Christofides, 1995; Achberger et al., 2002) or grid points from different numerical models (e.g., Frank and Landberg (1997); Mortensen et al. (2006)) can be extrapolated to the location of interest. However, this is problematic due to the high spatial variability of the wind field. The latter include meteorological reanalysis projects (Kalnay et al., 1996; Compo et al., 2011) and Circulation Models at Global (GCMs) and Regional (RCMs) scales (e.g., Skamarock et al. (2005)). Reanalyses usually provide a long enough time series, although they comprise spatial resolutions coarser than $0.5^{\circ} \times 0.5^{\circ}$. On the opposite side, RCMs have the ability to employ reanalysis, GCMs or observations to dynamically downscale the weather conditions into a mesoscale/local scale. This is done by performing a series of nested simulations, where the output data from a coarser and wider domain is employed as input for an inner and more resolved domain. Although they can reach a model resolution lower than $5 \mathrm{~km}$, they rarely exceed two or three decades due to the uncertainty increase of the data (observations, reanalysis or GCMs) assimilation process and the high computational cost of the simulations. These difficulties, together with the high spatial variability 
of local wind (specially under complex orography), will generally prevent most of these approaches to be effectively used for the long-term wind variability at a given location.

As an alternative to numerical models, statistical methods can often provide an efficient approach to resolve the local wind regime. They have been widely applied to downscale local wind by employing tools like WAsP (Mortensen et al., 1993) or using some information on the circulation at synoptic scale (e.g., Barnett and Preisendorfer (1987); Busuioc et al. (2008)) as predictor. This is usually made by applying some type of clustering or classifier to pressure-related data (SLP, Z850, etc) in order to obtain the so-called circulation, weather or wind types. The use of these patterns also helps to prevent the risk of overfitting in a non-linear problem as an atmospheric downscaling (Hawkins, 2004). Thus, several objective methods for the regional circulation clustering have been applied. Jenkinson and Collison (1977) developed an automatized classification based on the approximation of the geostrophic wind through gridded SLP data over the British Isles. This technique (known as Circulation Weather Types), was later performed over the Iberian Peninsula (Trigo and DaCamara, 2000; Spellman, 2000). Classifications based on eigenvectors have also been developed (e.g., Davis and Kalkstein (1990); Esteban et al. (2006); Romero et al. (1999); Jiménez et al. (2009)). Other works classified the circulation based on Euclidean distances, either through kmeans (García-Valero et al., 2012) or k-medoids (Hopke and Kaufman, 1990) from a Canonical Cluster Analysis (CCA) (Beranová and Huth, 2008).

Salameh et al. (2009) applied a k-means (Hartigan and Wong, 1979) classificator to a series of daily pressure fields previously clustered through a Principal Components Analysis to downscale the local flow, while García-Bustamante et al. (2012) applied a CCA to estimate 350 years of wind at a monthly scale. Pryor et al. (2005b) estimated surface wind speed by relating wind speed parameters to relative vorticity and surface pressure gradients. Mengelkamp (1999) designed a statistical-dynamical method by parameterizing and clustering geostrophic wind components and the vertical temperature gradient. Brayshaw et al. (2011) have successfully reproduced wind speed distributions using Markov models, extending artificially the length of time series. Other works developed wind speed downscaling through non-clustering methods. Sailor et al. (2000) coupled an Artificial Neural Network (ANN) to a GCM output to downscale wind speed in different climate change scenarios.

Evolutionary Algorithms (EA, Bäck (1996); Fonseca and Fleming (1995)) are addressed to face cluster or regression problems with a big amount of possible solutions. To achieve this, they search for an optimal solution by emulating some of 
the genetics laws in biology along a series of iterations or generations. They have also been used for the statistical downscaling of wind. EA have been employed for the correction of distortion sources of wind observations through Doppler radar (Chen et al., 2001), for the wind estimation where observations are scarce (Davy et al., 2010), or to predict short-term wind power production (Jursa and Rohrig, 2008). In Carro-Calvo et al. (2011, 2012) daily wind speed is reconstructed through an EA by classifying wind according to selected Sea Level Pressure (SLP) differences. However, the problem of long-term wind speed variability has been scarcely addressed through these techniques. Finally, in Kirchner-Bossi et al. (2013) an evolutionary algorithm allows reconstructing daily wind speed from SLP gridded data for almost 140 years, improving the accuracy of the NCEP/NCAR reanalysis (Kalnay et al., 1996) gridded surface wind.

In this paper we investigate the multidecadal variability of the wind power generated by a real wind turbine for two different case studies in Spain. To attain this, we reconstruct wind power from the 20CR renalysis project (Compo et al., 2011) during the period 1871-2009, by performing a statistical downscaling of wind that implements evolutionary computation techniques (Kirchner-Bossi et al., 2013). Next we estimate the wind power output by convoluting the reconstructed wind speed with a power curve from an industrial turbine.

The availability of a centennial wind power output series allows us to study its long-term relationship with the main teleconnection patterns and their stationarity. Finally, after analyzing the variability of the wind and wind power distributions, we derive a simple empirical model to estimate wind power output from the Weibull parameters.

\section{Annual Wind Power Output Estimation}

A realistic estimation of a market wind turbine annual power output $\left(P_{o}\right)$ can be computed by means of the matrix product between the wind speed PDF in the considered location and the Power Curve provided by the manufacturer. This curve provides the model-empirical relationship between the wind speed observations and the wind power output of the turbine (Hau, 2000).

Here we estimate the annual wind speed PDF for the period 1871-2009 by performing an statistical downscaling of the daily wind by relating two independent 
datasets: 1) the short-term wind speed observations from meteorological towers at different points of study, and 2) the long-term synoptic flow circulation derived from Sea Level Pressure (SLP) daily fields from the 20CR reanalysis model. Details are provided below.

\subsection{Wind Observations}

The considered wind observations belong to meteorological towers at two wind farms with very different orographic and circulation regimes, which have been also employed in other works (Carro-Calvo et al., 2011, 2012; Kirchner-Bossi et al., 2013). One of the towers (T1) is located in central-east Spain, while the other one (T2) stands at the Gibraltar Strait Area (Fig. 1). Wind data include the average speed and direction and maximum speed, recorded every ten minutes for the periods 1999-2009 (T1) and 2001-2009 (T2). These periods will be referred later as $T_{o b s}$.

Data quality of the series was controlled through the detection of missing data, and the persistence of zero values. In the first case, a few periods without data were detected along the observations. In a second exercise, zero wind values representing abrupt transitions from high winds were dismissed. Finally, only those days which preserved more than half of their 144 daily values were included in the analysis. After these considerations, the obtained series of daily mean wind showed a final length of 2623 days for $\mathrm{T} 2$ and 3448 days for $\mathrm{T} 1$. This is equivalent to 7.2 and 9.5 years of data respectively, which represent $94.4 \%$ and $95.1 \%$ of the original data. All the instruments considered follow the quality standard IEC 61400-12-1.

In this work we have considered the technical details of the Vestas V-82 1.65 MW MK II (Vestas, 2005) wind turbine. Since it has been employed in several research works (e.g., McIntyre et al. (2011); Tenguria et al. (2011); Schubel and Crossley (2012)), it can be considered as a reference in wind power research applications. The wind turbine V-82 hub height is different than the measures considered. In order to derive the wind speed $v(z)$ at a certain height $z$ where no measures are available, the Wind Profile Power Law model (Counihan, 1975) has been employed. It is defined as follows: 


$$
v(z)=v_{a}\left(\frac{z}{z_{a}}\right)^{\alpha}
$$

where

$$
\alpha=0.096\left(\log _{10}\left(z_{0}\right)\right)+0.016\left(\log _{10}\left(z_{0}\right)\right)^{2}+0.24
$$

denotes the contribution of the site roughness length $\left(z_{0}\right)$ to the speed vertical gradient of the atmospheric boundary layer, and $v_{a}$ is the known wind speed value at height $z_{a}$. In our case, T1 and T2 locations exhibit an $\alpha$ value of 0.20 . The expression has been applied here to estimate the daily wind speed at the turbine hub height $(z=78 \mathrm{~m})$ by considering the measured wind values $\left(v_{a}\right)$ and their height $\left(z_{a}=41.5\right.$ and $z_{a}=40 \mathrm{~m}$, respectively for $\mathrm{T} 1$ and $\left.\mathrm{T} 2\right)$.

\subsection{The 20th Century Renalisys Version 2}

Sea Level Pressure daily (SLP) fields at 1200 GMT have been retrieved from the 56 ensemble members of the second version of the "Twentieth Century Reanalysis" Project (20CR, Compo et al. (2011)), spanning from 1871 to 2009 ( $\left.T_{\text {rec }}\right)$ with a resolution of $2 \times 2$ degrees.

$20 C R$ was computed by applying an Ensemble Kalman Filter to the background 'first guess' supplied by a set of 56 forecasts obtained from the GFS prediction model ran globally. In this way, the $20 C R$ resulted in an ensemble of 56 independent simulations. It should be stressed that the $20 \mathrm{CR}$ dataset represents the only available 3-D reanalysis dataset going back to 1871. By generating an ensemble of likely upper-air fields that are dynamically consistent with concurrent and previous pressure observations fields it provides a useful estimation of the uncertainty in the analysis fields at each analysis time (Compo et al., 2011).

It has been shown that the reanalysis for the early decades is particularly robust for mid-latitude regions with plenty of SLP data at the time (i.e. Europe and North America), being considerably less accurate outside these regions (Compo et al., 2011).

The fact of considering the SLP ensemble mean of the 56 simulations could entail a 
loss of information (Donat et al., 2011) due to smoothing effects specially in storms (Wang et al., 2012). To avoid this problem, the 20CR-derived variables computed in this paper have been obtained by considering each one of the 56 ensemble components independently. Only after computing the final derived variables, their mean and spread were calculated from the 56 outputs, as described in the following sections.

\subsection{Statistical Downscaling of Daily Wind}

The statistical downscaling of the daily wind conditions at the given sites was performed by relating the local scale mast observations (predictand) with the corresponding state of the daily large-scale circulation derived from the SLP field (predictor), in order to reconstruct the daily wind conditions at those periods where no observations are available.

The parametrization of the predictor is based on the geostrophic flow. Its origin, magnitude and vorticity can be derived through a set of indices (flow intensity $F$ and vorticity Z, e.g., Jenkinson and Collison (1977)), by considering the SLP field. We have clustered this predictor to reduce the dimensions of a complex problem as relating two different spatiotemporal scales at the atmospheric dynamics, in order to prevent the risk of overfitting at the downscaling process. In this work we will classify and statistically downscale the daily wind conditions by employing the Wind Types (WT) technique introduced in Kirchner-Bossi et al. (2013) (referred there as FE method).

The days from the observations period $\left(T_{o b s}\right)$ are clustered according to similar large-scale wind features, according to their daily values of $F$ and $Z$. This is done by stratifying the $F$ vector space through a series angular and radial borders. A sample solution for this stratification is shown in Figure 2. The stratification is performed according to eight angular borders, which at the same time are divided by three radial borders, so that the 24 borders produce an overall amount of 24 sections. Additionally, a central region over the $F$ space is defined, which in turn classifies the very low wind flow according to its vorticity sign (cyclonic or anticyclonic), finally producing a classificator with $26 \mathrm{WT}$.

The way the angular and the radial borders are fixed is defined through an Evolutionary Algorithm. This consists on implementing a series of procedures as crossovers and mutations between possible solutions (individuals) within an iter- 
ative process, with the aim of minimizing the average $F$ dispersion per cluster, defined through the following Cost Function:

$$
\Phi_{F}(J)=\frac{1}{\tau_{r}} \sum_{\kappa=1}^{n} \sum_{i \in c_{\kappa}}\left|F_{c_{\kappa}}-F_{i}\right|
$$

where $r_{i}$ stands for a generic day of the period considered, and $F_{c_{\kappa}}$ stands for the average of $F$ values within a certain class $c_{\kappa}$. After 3000 iterations or generations the individual or configuration with the minimum cost function is selected to classify the daily wind conditions.

Finally, since the classificator is developed for the period where wind observations are available, each one of the 26 obtained WTs can be characterized with local wind data.

The method, cross-validated in Kirchner-Bossi et al. (2013), showed daily wind speed estimations with a Mean Absolute Error significantly lower than those computed for other approaches, as the regressed surface wind speed form the NCEP/NCAR reanalysis.

\subsection{Annual Wind Speed PDFs estimation}

The previous method (WT) was applied individually to each one of the 56 ensemble members of the $20 \mathrm{CR}$ reanalysis to reconstruct the annual wind speed PDFs (1871-2009). Each one of them was thus obtained as summarized in the following procedure, where the period employed every time $\left(T_{o b s}\right.$ or $\left.T_{r e c}\right)$ is specified:

(1) First of all, the WT classificator is computed, according to the daily $F$ and $\mathrm{Z}$ values derived from $20 \mathrm{CR}$ ( $T_{\text {obs }}$, although no observations are used here).

(2) The 10-min wind observations of those days belonging to the same WT are employed to compute a wind speed PDF. This is done for every WT, so finally 26 WT-PDFs are obtained, each one of them characterizing every WT with information on the local wind speed regime $\left(T_{o b s}\right)$.

(3) The classificator is then employed to derive a Wind Type for every day of $T_{\text {rec }}$. Thus, now every one of these days can be characterized with a certain 


\section{WT-PDF.}

(4) For each year $\left(T_{r e c}\right)$, a PDF is computed by aggregating all its daily PDFs. The same process was performed seasonally: December-February (DJF), MarchMay (MAM), June-August (JJA) and September-October(SON).

(5) Since steps 1-4 were applied to each one of the 56 ensemble components of the $20 C R$ SLP dataset, at last a set of 56 wind speed PDFs is obtained for every year/season $\left(T_{r e c}\right)$.

Finally, since the reconstructed daily wind speed has been computed from a high time resolution (10-minute data) homogeneous data, the computed PDFs are directly multiplied by the Power Curve (fig. 3) of the V-82 wind turbine.

\section{Annual Wind Power Output Series (1871-2009)}

Since the reconstructed PDFs series consist of 56 annual PDFs, 56 values of $P_{o}$ where obtained for every year. Fig. 4 shows the evolution of the annual $(a-b)$ and seasonal $(c-j) P_{o}$. The observed $P_{o}$ dispersion is represented in the figures through the 10, 25, 50, 75, 90 percentiles and the maximum and minimum values of the simulated $P_{o}$ ensembles. The reduction in the $P_{o}$ dispersion with time is clearly evidenced. The ensemble outputs are increasingly similar according to the accuracy improvements of the $20 C R$ inputs with time. In fact, this spread is partially related to the quality of the $20 \mathrm{CR}$ reconstruction for that year, largely dependent on the number of stations providing pressure data in the area (Compo et al., 2011). Therefore, it is expected that errors increase as we go into the early decades of the 20CR dataset. Furthermore, the quality of reconstructed fields decreases between northern and southern Iberia (see Fig. 9 in Ref. Compo et al. (2011)), a fact that may contribute to the wider spread of values observed for southern T2 in comparison with T1.

Along the $T_{o b s}$ period, we have compared the average simulated $P_{o}$ with the annual power values obtained from the wind observations (depicted in green in Fig. 4). The obtained mean $P_{o}$ values at $\mathrm{T} 1$ were $666 \mathrm{Kw}$ (obs.) and $661 \mathrm{Kw}$ (rec.). At $\mathrm{T} 2$ these values were respectively $582 \mathrm{Kw}$ (obs.) and $585 \mathrm{Kw}$ (rec.). At an interannual scale, the comparison throughout this period resulted in MAE values 
of $26.59 \mathrm{Kw}$ (T1) and $31.64 \mathrm{Kw}$ (T2) with respect to the power computed with the wind observations.

\subsection{Long-Term Variability of the simulated Power Output}

Both towers exhibit high interannual variability superimposed on long-term patterns. In T1 $P_{o}$ reached its peak in the $1910 \mathrm{~s}(813 \mathrm{~kW})$ and has experimented a continuous decline since then. In fact, it shows an annual statistically significant $(\mathrm{p}<0.05$, similar for the whole paper) negative trend of $-41 \mathrm{~kW}(-5.6 \%)$ per 100 years (hereafter all trend changes refer to this period), with a minimum value in $1953(602 \mathrm{~kW})$, and the lowest decadal values in the last period of the series. In T2 $P_{o}$ shows an opposite behavior, with the minimum values in the beginning of the 20th century $(485 \mathrm{~kW}$ in 1911) and highest values after 1940 peaking in the last 30 years (maximum in 1978, $644 \mathrm{~kW}$ ).

Seasonally, at T1 the biggest decrease was observed at JJA, with a significant trend of $-13 \mathrm{~kW} / 100$ years, with all seasons showing negative trends (also significant in MAM). At T2 the overall increase of the annual series is mostly attributable to SON, which shows a positive trend of $+16.0 \%$, although all seasons presented positive trends (all significant except MAM). During the second half of the 20th century the increase at SON and DJF is clearly evidenced. Particularly, the last 10 years show even a higher growth at MAM and JJA, with a JJA difference of means of $12,9 \mathrm{~kW}(+7.6 \%)$ with respect to the previous 130 years.

T1 shows a clear seasonal cycle, with higher $P_{o}$ values in DJF (30\% of the overall $\left.P_{o}\right)$ than in JJA (19.5\%). However, it is less pronounced at T2, with an almost even distribution of power among the seasons (27 and $22.2 \%$ for DJF and JJA resp.). The observed high summer contribution is consistent with wind regimes at its location (Gibraltar Strait), since summer winds (prevailingly easterly) are there specially strong compared to other points of Iberia.

Multidecadal periodicities modulate the observed trends. A spectral Fourier analysis performed on the annual series showed the existence of several statistically significant interdecadal and multidecadal cyclic fluctuations at T1 (27 yr) and T2 (46 and $13 \mathrm{yr}$ ). At T1 the annual signal seems to be spread among all seasons, as no long-term significant cycles were found for any specific season. In turn, T2 periodicities evidenced the main contribution of JJA (46 and 13y) and SON (13y) to these multidecadal fluctuations. In the case of JJA, the $46 y$ cycle could be 
directly contributing to the last decade increase. Tables 1 and 2 summarize the obtained results for the annual and seasonal series.

\subsection{Impact of the Teleconnection Patterns on the simulated Output Power}

The low-frequency (annual, seasonal) variability of the atmospheric circulation at regional scale can be described through a small number of large-scale or teleconnection (TC) patterns, which hold the biggest ratio of explained variance. Different works have investigated their relationship with the wind power output (Harper et al., 2007; Brayshaw et al., 2011; Jerez et al., 2013; Jerez and Trigo, 2013). The main TC patterns (or modes) over the North Atlantic-Europe Region are the North Atlantic Oscillation (NAO), the Eastern Atlantic (EA) pattern and the Scandinavia (SCAND) pattern (Barnston and Livezey (1987)). Here we investigate the impact of these TCs on the wind power variability at the two regions considered in the IP, as well as the stationarity of these connections.

All three indices where obtained from the NOAA Climate Prediction Center (Bell et al., 2013). There, a Rotated Principal Component Analysis (RPCA) is performed to the $500 \mathrm{hPa}$ field from the NCEP/NCAR (Kalnay et al., 1996) reanalysis for the period 1950-2009, which ensures the linear independence between them over time. Additionally, the $P_{o}$ series have been compared to the Atlantic Multidecadal Oscillation (AMO, Kaplan et al. (1998); Enfield et al. (2001)), computed in terms of the Sea Surface Temperature (SST) at the Atlantic Ocean with a detrend of its long-term linear signal. This index has been included in this analysis, since the Atlantic oceanic circulation could be relevant to explain the low frequency of the wind variability.

The influence of the teleconnection patterns on $P_{o}$ has been analyzed in terms of the variance explained by the TCs (computed as the square of the Pearson correlation coefficient, $r^{2}\left(T C, P_{o}\right)$ ), along the available period. The period where the three indices are available is 1950-2009. A 30-year running window was used to investigate the temporal stationarity of the relationship along the considered period. Figure 5 shows the variance explained by the three most important modes (NAO, EA, SCAND) for each season, where the horizontal axis values represents the central year of the $30-y r$ period.

Results show that $P_{o}$ is more closely associated to large-scale circulation modes in $\mathrm{T} 1$ than in T2. At T1 the overall explained variance is particularly high in autumn 
(highest in 1993, 79\%) and winter (peaking at 69\% in 1967), with a major contribution of SCAND and NAO respectively. In JJA this tower shows a high coupling with respect to $\mathrm{NAO}$, although it is highly non-stationary, with an abrupt decrease in the last years until loosing significance. Finally, MAM shows a stationary weak but mostly significant contribution from each one of the three modes. Regarding $\mathrm{T} 2$, SON is the only season with significant results. Nonetheless it shows, as in T1, a high and stationary SCAND explained variance (peaking at 51\%). Interestingly, in SON the sign of Pearson correlation between SCAND and T1 is opposite to that at T2, which can explain the reported differences in wind power production regimes between both locations.

Finally, the AMO index (considered for the whole period, 1871-2009) shows a non stationary (although slightly significant) correlation with both towers (Fig. 6), switching its sign during the considered period. The correlation with T1 shows an opposite behavior compared to that obtained with T2 throughout the entire period. It is significantly correlated with $\mathrm{T} 2$ since 1966 (with a maximum $\mathrm{r}=0.49$ ), while T1 (negatively) does so since 1977. The most correlated season with AMO is MAM (T2), with $\mathrm{r}=0.48$ during 1950-1980.

\subsection{Incidence of the Weibull parameters on the Output Power Variability}

An usual resource to expand the information on the prevailing wind speed regime consists on fitting a Weibull distribution to the wind speed PDF, specially when the available wind speed data is scarce (e.g., ?Seguro and Lambert (2000); ?). This way a smoothed curve fully described through exclusively two parameters (shape $k$, dimensionless, and scale $c,[\mathrm{~m} / \mathrm{s}])$ can be obtained. In this section the long-term variability of the average annual wind speed PDF is analyzed in terms of these parameters, which are then compared with the $P_{o}$ long-term variability in order to explore the empirical relationships existing among them.

As a first step, the mean value from the set of 56 annual PDFs previously obtained was computed for each year. Then, the Weibull fit of every average annual PDF was performed by considering the log-linear expression obtained for a certain probability $P_{i}$ to record a wind speed $v<v_{i}$ (Miller et al., 1965). Since the Weibull $\operatorname{PDF}\left(P_{W}\right)$ is defined as 


$$
P_{W}(v)=\frac{k}{c}\left(\frac{v}{c}\right)^{k-1} \mathrm{e}^{-\left(\frac{v}{c}\right)^{k}}
$$

it can be verified that its Cumulative Distribution Function (CVF) for the probability $P_{i}$ to register a wind speed $v<v_{i}$ is

$$
P_{i}\left(v<v_{i}\right)=1-\mathrm{e}^{-\left(\frac{v}{c}\right)^{k}}
$$

If a natural logarithm is applied twice, the following linear expression is obtained:

$$
\ln \left[-\ln \left(1-P_{i}\right)\right]=k \ln \left(v_{i}\right)-k \ln c
$$

By considering $\ln \left[-\ln \left(1-P_{i}\right)\right]$ as the dependent variable and $\ln \left(v_{i}\right)$ the independent one, $k$ becomes the slope of the line and $-k \ln c$ the intercept with the $\mathrm{y}$-axis. This way, for every year at T1 and T2 a linear fit was performed for 200 values of $v_{i}$ obtained by defining wind speed intervals with an amplitude of $0.1 \mathrm{~m} / \mathrm{s}$ along a speed range between 1.5 and $21.5 \mathrm{~m} / \mathrm{s}$. With them and their corresponding values of $P_{i}$ the 139 annual values of $k$ and $c$ were obtained.

Figure 7 shows the corresponding fittings of the Weibull function for the average annual wind speed PDFs for T1 and T2, for each one of the 139 years. Then, a colour code allows to assess the evolution of these annual curves trough the entire period. It can be seen that wind speed PDFs change differently with time depending on the site. Thus, at T1 the wind speed mode (the curve maximum) and the tail of the curve are reduced, which evidences a decrease in high and intermediate wind speed frequencies. On the contrary, in the T2 Weibull curve the frequency of intermediate (high) speeds is reduced (increased).

These morphological changes can be observed through the long-term variability of the Weibull parameters (Table 3). In this sense, a statistically significant negative (positive) trend was detected for $c$ time series at T1 (T2). These results are consistent withe the values obtained for $P_{o}$, and the fact that $c$ is more closely related with wind speed than $k$ (Seguro and Lambert, 2000). This implies a sharpening (flattering) of the corresponding distribution, as seen in the figure. A negative trend (also significant) was detected in the annual series of $k$ for both towers. A decrease in $k$ values should imply a translation to the left of the distribution mode, which is evidenced at T1. In turn, at T2 the contribution of $k$ appears to be overshadowed by the larger increment of $c$. In this sense, the coefficient of variation 
$\left(C_{v}\right)$ of $c$ doubles that of $k$. Finally, a spectral analysis through a Fourier transform of the series also showed the existence of statistically significant low frequency cycles, one of 27 years for $k$ (T2) and 13 years for $c$ (both towers), in line with the $P_{o}$ reported periodicities.

Once the multidecadal variability of the Weibull parameters was analyzed, its relationship with the $P_{o}$ signal was explored. We computed linear regression coefficients between $P_{o}$ and $c$ and $k$, one at a time. As expected according to their definition, the contribution of $c\left(r^{2}=0.95\right.$ at both towers) was clearly higher than that for $k\left(r^{2}=0.52\right.$ at $\mathrm{T} 1, r^{2}=0.18$ at $\left.\mathrm{T} 2\right)$, although the value of the latter was also statistically significant. Additionally, the partial correlations of $c$ and $k$ with $P_{o}$ (understood as the correlation of one parameter with $P_{o}$ by removing the effects of the other parameter) were also statistically significant. These results are represented in Figure 8. One the one hand, the parameter trends are reflected in terms of a clear differentiation between past (blue dots) and recent years (red dots). On the other hand, the negative (positive) historical trends of the $P_{o}$ at T1 (T2) can be also noted.

The significant couplings of both parameters to $P_{o}$ and the availability of nearly 140 years of annual wind speed PDFs and power output values led us to explore models for the estimation of the annual wind power output by only considering the information of the Weibull distribution. As a standard procedure, the annual wind power output was estimated by employing the traditional Weibull-fitted PDF and the turbine Power Curve. However, RMSE values of $115 \mathrm{~kW}$ and $53 \mathrm{~kW}$ where observed for T1 and T2 respectively when compared with the $P_{o}$ series. This can be due to the fact that the goodness-of-fit of this adjustment is not always as accurate as desired (García-Bustamante et al., 2008), specially when the orthogonal components of the horizontal wind differ from a normal distribution (Tuller and Brett, 1984), mainly in low wind speeds (Jamil et al., 1995).

These poor results obtained with the standard Weibull-fitted wind speed PDF power model led us to investigate a novel model for $P_{o}$ based uniquely on the parameters $c$ and $k$. Accordingly, a multilinear fit was performed by regressing the 139 annual values of $k$ and $c$ on $P_{o}$, which led to the obtention of these expressions for the annual wind power output model:

$$
\begin{aligned}
& T 1: P_{1}(k, c)=-989+256 k+113 c(k W) \\
& T 2: P_{2}(k, c)=-757+281 k+103 c(k W)
\end{aligned}
$$

They denote a positive contribution of both parameters at both towers, which is 
consistent with its theoretical definition. The fitted expression of power showed coefficients of determination $\left(R^{2}\right)$ of 0.99 and 0.98 for T1 and T2 respectively, reflecting that this simple equation can describe the $P_{o}$ variability in terms of $c$ and $k$ only.

The validation of these multilinear regressions showed RMSE values with respect to $P_{o}$ significantly smaller ( 3.3 and $4.8 \mathrm{Kw}$ for $\mathrm{T} 1$ and $\left.\mathrm{T} 2 \mathrm{resp}.\right)$ than those obtained through the PDF curves fitted to Weibull. This means that in both cases the linear combination of $c$ and $k$ is able to describe the $P_{o}$ variability more accurately than the fitted curves. For this reason, this multiple linear fit represents a simple way to estimate the annual $P_{o}$ of a prospective wind turbine for periods where wind data are available but wind power data are not. Particularly, it constitutes a useful solution at those sites where $c$ and $k$ values have been computed for a few years, without the need to await for a good wind PDF approximation by the Weibull function.

\section{Summary and Conclusions}

The implementation of an ad-hoc wind speed statistical downscaling technique has allowed us to simulate the annual wind power output for wind turbines located at two different sites in Spain during almost 140 years (1871-2009). This has permitted to investigate the long-term variability of wind power output in both places. The impact of the prevailing large-scale circulation patterns on the generated wind power has been investigated. Furthermore, the multi-decadal changes of several parameters associated to power output, as the wind speed PDFs Weibull values $k$ and $c$ have also been analyzed, and a linear model for wind power exclusively depending on them has been computed.

The MAEs between wind power output obtained through wind observations and wind reconstructions for the observational period of about 5 (T1) and $3 \mathrm{~kW}$ (T2) highlight the suitability of the employed technique to assess the long-term wind power production of a wind turbine. The simulated annual output power on the case study with the Vestas V-82 (1.65 MW) turbine showed a very different variability depending on the selected tower. Significant long-term trends were found for both locations. An overall power output decrease was observed in T1, the tower in central Spain $(-6 \%, 41 \mathrm{~kW}$ in $100 \mathrm{yr}$.), while a long-term increase was detected 
in T2, the tower located in the Gibraltar Strait area $(7 \%, 37 \mathrm{~kW}$ in $100 \mathrm{yr} .8 \%$ in JJA). All these changes became particularly significant during the second part of the 20th century, independently of their dispersion reduction. So, the observed record (1999-2009) corresponds to minimum (T1) and maximum (T2) extremes in a centennial context. This new perspective can entail important implications in the long-term planning of wind farms in these regions. Thus, if sustained in time, changes in output power frequencies (specially at T2) could entail the need to consider some changes in the wind turbine features in a wind farm layout or in further repowerings. Finally, the seasonal cycle is not detected at T2 due to the high contribution to power output at JJA consistent (CL20 at Esteban et al. (2006)) with the anticyclonic circulation regime in summer over Iberia (Fernández-Montes et al., 2012; García-Herrera et al., 2005).

All the magnitudes derived from the reconstructed wind show periodicities in the multidecadal band, from 13, 25 to 46 years. Similar bands were detected in (Kirchner-Bossi et al., 2013). Interestingly, variability in the $25 y$ band has also been detected in the observed wind direction in the English Channel (Barriopedro et al., 2013), suggesting that this multidecadal variability may not result from an artifact derived from the reconstruction process. The origin of this type of wind variability is still unclear and is subject of current research.

Results on the impact of the main large-scale circulation modes at the EuroAtlantic region over wind power at the IP show a high dependency on the considered site, showing a higher impact at T1 than T2. It also shows a high dependency on the season, with maximum values for SCAND in both towers, being non-stationary in some cases (DJF and JJA at T1). The sign of the correlations with NAO and SCAND is opposite in T1 with respect to T2. While T1 is placed in the north of the Iberian plateau, more directly exposed to Atlantic and regional regimes, T2, close to the Gibraltar Strait, is mostly affected by the persistent easterly winds, which entail a prevailing contribution to wind power (Jerez and Trigo (2013), fig. 3). These results are consistent with the spatial configuration of the SCAND pattern and its variability mode center over Iberia (Barnston and Livezey (1987), SCAND as Eurasia-1). The coupling of the obtained power series with the AMO index also evidences this contrary variability between locations. This high variability in the relationship between the output power and large-scale climate should be taken into account when downscaling models at seasonal and larger time scales.

The availability of a 139 year PDFs series and output power values has allowed the assessment of the empirical relationship between the annual generated power and the Weibull parameters $k$ and $c$, once the obtained annual PDFs where ad- 
justed to that function. First, the long-term variability of these parameters showed variations up to 5\% every 100 years ( $c$ at T2), and periodicities of $13(c)$ and 27 ( $k$ at T2) years. After obtaining significant relationships between each one of the parameters individually and the simulated annual wind power, a multilinear regression model of annual wind power was derived, depending only on the Weibull parameters. This approach was validated by showing an improved estimation of the simulated output power as compared with classical ways, resulting an appropriate model for situations where $k$ and $c$ data are available but a an accurate fit of the speed distribution to a Weibull function can not be guaranteed. The horizon of application of the model is spread out when considering the various contributions on wind reconstruction and climate projection which provide a wind prediction only in terms of the Weibull function (e.g., Bogardi and Matyasovzky (1996); Pryor et al. (2005a); Curry et al. (2012)).

Summing up, this work provides a methodology which allows to analyze the longterm wind power output variability through the obtention of a realistic centennial simulation of daily values generated by a wind turbine. This has made possible to estimate the range of expectable values of wind power at annual scales, to understand the observed values in a centennial context, and to provide a benchmark for variability ranges derived for climate change projections.

\section{Acknowledgements}

This work has been supported by the research framework established between S.t.r.e.a.m. group at University Complutense of Madrid and Iberdrola Renovables Energía S.A., through a fellowship program under Art. 83 of L.O.U. 


\section{References}

Achberger, C., M. Ekström, and L. Bärring (2002). Estimation of local nearsurface wind conditions-a comparison of wasp and regression based techniques. Meteorological Applications 9(2), 211-221.

Archer, C. L. and M. Z. Jacobson (2003). Spatial and temporal distributions of us winds and wind power at $80 \mathrm{~m}$ derived from measurements. Journal of Geophysical Research 108(D9), 4289.

Bäck, T. (1996). Evolutionary algorithms in theory and practice: evolution strategies, evolutionary programming, genetic algorithms, Volume 996. Oxford university press Oxford.

Barnett, T. and R. Preisendorfer (1987). Origins and levels of monthly and seasonal forecast skill for United States surface air temperatures determined by canonical correlation analysis. Monthly Weather Review 115(9), 1825-1850.

Barnston, A. G. and R. E. Livezey (1987). Classification, seasonality and persistence of low-frequency atmospheric circulation patterns. Monthly weather review 115(6), 1083-1126.

Barriopedro, D., D. Gallego, M. Alvarez-Castro, and R. García-Herrera (2013). Witnessing North Atlantic westerlies variability from ships logbooks (16852008). Climate Dynamics 2013.

Bayray, M., A. Mustefa, F. Yohannes, H. Kiros, A. Haileslasie, P. Gebray, M. Hayelom, and A. Dagne (2013). Wind energy data analysis and resource mapping of geba catchment, north ethiopia. Wind Engineering 37(4), 333-346.

Bell, G. D., S. Wei, M. L'Heureux, and M. Halpert (2013). Northern Hemisphere teleconnection patterns. Climate Diagnostics Bulletin May, 2013.

Beranová, R. and R. Huth (2008). Time variations of the effects of circulation variability modes on European temperature and precipitation in winter. International Journal of Climatology 28(2), 139-158.

Bogardi, I. and I. Matyasovzky (1996). Estimating daily wind speed under climate change. Solar Energy 57(3), 239-248.

Brayshaw, D. J., A. Troccoli, R. Fordham, and J. Methven (2011). The impact of large scale atmospheric circulation patterns on wind power generation and its potential predictability: A case study over the UK. Renewable Energy 36(8), 2087-2096.

Busuioc, A., R. Tomozeiu, and C. Cacciamani (2008). Statistical downscaling model based on canonical correlation analysis for winter extreme precipitation events in the Emilia-Romagna region. International Journal of Climatology 28(4), 449-464.

Carro-Calvo, L., S. Salcedo-Sanz, N. Kirchner-Bossi, A. Portilla-Figueras, L. Prieto, R. Garcia-Herrera, and E. Hernández-Martín (2011). Extraction of synoptic 
pressure patterns for long-term wind speed estimation in wind farms using evolutionary computing. Energy 36(3), 1571-1581.

Carro-Calvo, L., S. Salcedo-Sanz, L. Prieto, N. Kirchner-Bossi, A. PortillaFigueras, and S. Jiménez-Fernández (2012). Wind speed reconstruction from synoptic pressure patterns using an evolutionary algorithm. Applied Energy $89(1), 347-354$.

Celik, A. N. (2004). A statistical analysis of wind power density based on the Weibull and Rayleigh models at the southern region of Turkey. Renewable energy 29(4), 593-604.

Chen, Y.-W., N. Mendoza, S. Uehara, Z. Nakao, T. Adachi, and Y. Masuda (2001). Estimating wind speed in lower atmosphere wind profiler based on genetic algorithms. In Instrumentation and Measurement Technology Conference, 2001. IMTC 2001. Proceedings of the 18th IEEE, Volume 2, pp. 1258-1263. IEEE.

Compo, G. P., J. S. Whitaker, P. D. Sardeshmukh, N. Matsui, R. Allan, X. Yin, B. Gleason, R. Vose, G. Rutledge, P. Bessemoulin, et al. (2011). The twentieth century reanalysis project. Quarterly Journal of the Royal Meteorological Society 137(654), 1-28.

Counihan, J. (1975). Adiabatic atmospheric boundary layers: a review and analysis of data from the period 1880-1972. Atmospheric Environment (1967) 9(10), 871-905.

Curry, C. L., D. van der Kamp, and A. H. Monahan (2012). Statistical downscaling of historical monthly mean winds over a coastal region of complex terrain. I. Predicting wind speed. Climate dynamics 38(7-8), 1281-1299.

Davis, R. E. and L. S. Kalkstein (1990). Development of an automated spatial synoptic climatological classification. International Journal of Climatology 10(8), 769-794.

Davy, R. J., M. J. Woods, C. J. Russell, and P. A. Coppin (2010). Statistical downscaling of wind variability from meteorological fields. Boundary-layer meteorology 135(1), 161-175.

Donat, M., D. Renggli, S. Wild, L. Alexander, G. Leckebusch, and U. Ulbrich (2011). Reanalysis suggests long-term upward trends in European storminess since 1871. Geophysical Research Letters $38(14)$.

Earl, N., S. Dorling, R. Hewston, and R. von Glasow (2013). 1980-2010 Variability in UK Surface Wind Climate. Journal of Climate 26(4), 1172-1191.

Energinet (2013). Consolidated annual report 2012. Energinet.dk Annual Reports.

Enfield, D. B., A. M. Mestas-Nuñez, and P. J. Trimble (2001). The Atlantic multidecadal oscillation and its relation to rainfall and river flows in the continental US. Geophysical Research Letters 28(10), 2077-2080.

Esteban, P., J. Martin-Vide, and M. Mases (2006). Daily atmospheric circulation catalogue for Western Europe using multivariate techniques. International journal of climatology 26(11), 1501-1515. 
Fernández-Montes, S., F. S. Rodrigo, S. Seubert, and P. M. Sousa (2012). Spring and summer extreme temperatures in Iberia during last century in relation to circulation types. Atmospheric Research.

Fertig, E., J. Apt, P. Jaramillo, and W. Katzenstein (2012). The effect of longdistance interconnection on wind power variability. Environmental Research Letters 7(3), 034017.

Fonseca, C. M. and P. J. Fleming (1995). An overview of evolutionary algorithms in multiobjective optimization. Evolutionary computation 3(1), 1-16.

Frank, H. and L. Landberg (1997). Modelling the wind climate of ireland. Boundary-Layer Meteorology 85(3), 359-377.

Frehlich, R. (2013). Scanning Doppler Lidar for Input into Short-Term Wind Power Forecasts. Journal of Atmospheric and Oceanic Technology 30(2), 230-244.

García-Bustamante, E., J. González-Rouco, P. Jiménez, J. Navarro, and J. Montávez (2008). The influence of the Weibull assumption in monthly wind energy estimation. Wind Energy 11(5), 483-502.

García-Bustamante, E., J. González-Rouco, J. Navarro, E. Xoplaki, P. Jiménez, and J. Montávez (2012). North Atlantic atmospheric circulation and surface wind in the Northeast of the Iberian Peninsula: uncertainty and long term downscaled variability. Climate dynamics 38(1-2), 141-160.

García-Herrera, R., J. Díaz, R. Trigo, and E. Hernández (2005). Extreme summer temperatures in Iberia: health impacts and associated synoptic conditions. In Annales Geophysicae, Volume 23, pp. 239-251. Copernicus GmbH.

García-Valero, J. A., J. P. Montavez, S. Jerez, J. J. Gómez-Navarro, R. LorentePlazas, and P. Jiménez-Guerrero (2012). A seasonal study of the atmospheric dynamics over the Iberian Peninsula based on circulation types. Theoretical and Applied Climatology 110(1-2), 291-310.

Giebel, G., R. Brownsword, G. Kariniotakis, M. Denhard, and C. Draxl (2011). The state-of-the-art in short-term prediction of wind power: A literature overview. Technical report, ANEMOS. plus.

Harper, B. R., R. W. Katz, and R. C. Harriss (2007). Statistical methods for quantifying the effect of the El Niño-Southern Oscillation on wind power in the northern Great Plains of the United States. Wind Engineering 31(3), 123-137.

Hartigan, J. A. and M. A. Wong (1979). Algorithm AS 136: A k-means clustering algorithm. Journal of the Royal Statistical Society. Series C (Applied Statistics) 28(1), 100-108.

Hau, E. (2000). Windturbines. Springer Berlin.

Hawkins, D. M. (2004). The problem of overfitting. Journal of chemical information and computer sciences 44(1), 1-12.

Hopke, P. K. and L. Kaufman (1990). The use of sampling to cluster large data sets. Chemometrics and intelligent laboratory systems 8(2), 195-204.

Jamil, M., S. Parsa, and M. Majidi (1995). Wind power statistics and an evaluation 
of wind energy density. Renewable energy 6(5), 623-628.

Jenkinson, A. and F. Collison (1977). An initial climatology of gales over the North Sea. Synoptic Climatology Branch Memorandum 62, 18.

Jerez, S. and R. Trigo (2013). Time-scale and extent at which large-scale circulation modes determine the wind and solar potential in the Iberian Peninsula. submitted (2013).

Jerez, S., R. Trigo, S. Vicente-Serrano, D. Pozo-Vázquez, R. Lorente-Plazas, J. Lorenzo-Lacruz, F. Santos-Alamillos, and J. Montávez (2013). The impact of the North Atlantic Oscillation on the renewable energy resources in southwestern Europe. Journal of Applied Meteorology and Climatology (2013).

Jiménez, P. A., J. F. González-Rouco, J. P. Montávez, E. García-Bustamante, and J. Navarro (2009). Climatology of wind patterns in the northeast of the Iberian Peninsula. International Journal of Climatology 29(4), 501-525.

Jursa, R. and K. Rohrig (2008). Short-term wind power forecasting using evolutionary algorithms for the automated specification of artificial intelligence models. International Journal of Forecasting 24(4), 694-709.

Kalnay, E., M. Kanamitsu, R. Kistler, W. Collins, D. Deaven, L. Gandin, M. Iredell, S. Saha, G. White, J. Woollen, et al. (1996). The NCEP/NCAR 40year reanalysis project. Bulletin of the American meteorological Society 7r(3), 437-471.

Kaplan, A., M. A. Cane, Y. Kushnir, A. C. Clement, M. B. Blumenthal, and B. Rajagopalan (1998). Analyses of global sea surface temperature 1856-1991. Journal of Geophysical Research 103(C9), 18567-18.

Kirchner-Bossi, N., L. Prieto, R. García-Herrera, L. Carro-Calvo, and S. SalcedoSanz (2013). Multi-decadal variability in a centennial reconstruction of daily wind. Applied Energy 105, 30-46.

Lee, D. and R. Baldick (2012). Analyzing the variability of wind power output through the power spectral density. In Power and Energy Society General Meeting, 2012 IEEE, pp. 1-8. IEEE.

Manwell, J., J. McGowan, and A. Rogers (2002). Wind energy explained: theory, design and application. 2002. John WileyESSons Ltd, UK, 577.

Marti, I., G. Kariniotakis, P. Pinson, I. Sanchez, T. Nielsen, H. Madsen, G. Giebel, J. Usaola, A. M. Palomares, R. Brownsword, et al. (2006). Evaluation of advanced wind power forecasting models-results of the anemos project. In Proceedings of the European Wind Energy Conference, EWEC 2006.

Martner, B. E. and J. D. Marwitz (1982). Wind characteristics in southern wyoming. Journal of Applied Meteorology 21, 1815-1827.

McIntyre, J. H., W. D. Lubitz, and W. H. Stiver (2011). Local wind-energy potential for the city of guelph, ontario (canada). Renewable Energy 36 (5), 1437-1446.

Mengelkamp, H.-T. (1999). Wind climate simulation over complex terrain and wind turbine energy output estimation. Theoretical and applied climatol- 
ogy 63(3-4), 129-139.

Miller, I., J. E. Freund, and R. A. Johnson (1965). Probability and statistics for engineers, Volume 4. Prentice-Hall Englewood Cliffs, NJ.

Mortensen, N. G., J. C. Hansen, J. Badger, B. H. Jørgensen, C. B. Hasager, U. S. Paulsen, O. F. Hansen, K. Enevoldsen, L. G. Youssef, U. S. Said, et al. (2006). Wind atlas for egypt: measurements, micro-and mesoscale modelling. In Proceedings of the 2006 European Wind Energy Conference and Exhibition, Athens, Greece, February, Volume 27, pp. 656.

Mortensen, N. G., L. Landberg, I. Troen, and E. Lundtang Petersen (1993). Wind atlas analysis and application program (wasp).

Palutikof, J. (1985). Variability in the wind field over the British Isles. Climate Monitor 14, 72-82.

Pashardes, S. and C. Christofides (1995). Statistical analysis of wind speed and direction in cyprus. Solar Energy 55(5), 405-414.

Pinson, P., C. Chevallier, and G. N. Kariniotakis (2007). Trading wind generation from short-term probabilistic forecasts of wind power. Power Systems, IEEE Transactions on 22(3), 1148-1156.

Pryor, S., J. Schoof, and R. Barthelmie (2005a). Climate change impacts on wind speeds and wind energy density in northern Europe: empirical downscaling of multiple AOGCMs. Climate Research 29(3), 183.

Pryor, S., J. T. Schoof, and R. Barthelmie (2005b). Empirical downscaling of wind speed probability distributions. Journal of Geophysical Research: Atmospheres (1984-2012) 110(D19).

REE (2012). El sistema eléctrico español. Avance del informe 2011. Red Eléctrica de España, S.A.U..

Reid, T., G. Baruzzi, I. Ozcer, D. Switchenko, and W. Habashi (2013). Fensap-ice simulation of icing on wind turbine blades, part 1: Performance degradation. In 51st AIAA Aerospace Sciences Meeting including the New Horizons Forum and Aerospace Exposition.

Ribrant, J. and L. Bertling (2007). Survey of failures in wind power systems with focus on Swedish wind power plants during 1997-2005. In Power Engineering Society General Meeting, 200\%. IEEE, pp. 1-8. IEEE.

Romero, R., G. Sumner, C. Ramis, and A. Genovés (1999). A classification of the atmospheric circulation patterns producing significant daily rainfall in the Spanish Mediterranean area. International Journal of Climatology 19(7), 765785.

Sailor, D., T. Hu, X. Li, and J. Rosen (2000). A neural network approach to local downscaling of GCM output for assessing wind power implications of climate change. Renewable Energy 19(3), 359-378.

Salameh, T., P. Drobinski, M. Vrac, and P. Naveau (2009). Statistical downscaling of near-surface wind over complex terrain in southern France. Meteorology and 
Atmospheric Physics 103(1-4), 253-265.

Sareen, A., C. A. Sapre, and M. S. Selig (2013). Effects of leading edge erosion on wind turbine blade performance. Wind Energy.

Schubel, P. J. and R. J. Crossley (2012). Wind Turbine Blade Design. Energies 5(9), 3425-3449.

Seguro, J. and T. Lambert (2000). Modern estimation of the parameters of the weibull wind speed distribution for wind energy analysis. Journal of Wind Engineering and Industrial Aerodynamics 85(1), 75-84.

Skamarock, W. C., J. B. Klemp, J. Dudhia, D. O. Gill, D. M. Barker, W. Wang, and J. G. Powers (2005). A description of the advanced research wrf version 2. Technical report, DTIC Document.

Spears, B. M. and I. D. Jones (2010). The long-term (1979-2005) effects of the North Atlantic Oscillation on wind-induced wave mixing in Loch Leven (Scotland). Hydrobiologia 646(1), 49-59.

Spellman, G. (2000). The application of an objective weather-typing system to the Iberian peninsula. Weather 55(10), 375-385.

Tenguria, N., N. Mittal, and S. Ahmed (2011). Evaluation of performance of horizontal axis Turbine Blades based on optimal rotor theory. Journal of Urban and Environmental Engineering (1), 15-23.

Trigo, R. M. and C. C. DaCamara (2000). Circulation weather types and their influence on the precipitation regime in Portugal. International Journal of Climatology 20(13), 1559-1581.

Tuller, S. E. and A. C. Brett (1984). The characteristics of wind velocity that favor the fitting of a Weibull distribution in wind speed analysis. Journal of Applied Meteorology 23, 124-134.

Vestas (2005). General Specifications V82-1.65 MW MK II. Vestas.

Wang, X. L., Y. Feng, G. Compo, V. Swail, F. Zwiers, R. Allan, and P. Sardeshmukh (2012). Trends and low frequency variability of extra-tropical cyclone activity in the ensemble of twentieth century reanalysis. Climate Dynamics, $1-26$.

Weibull, W. et al. (1951). A statistical distribution function of wide applicability. Journal of applied mechanics 18(3), 293-297. 
Table 1

Main statistics of the average $P_{o}$ annual and seasonal series for the period 1871-2001 at $\mathrm{T} 1$, including the mean, standard deviation $(\mathrm{SD})$, coefficient of variation $\left(C_{v}\right)$, significant trends expressed in \% every 100 years $\left(L T_{100 y r}\right)$ and the significant periodicities.

\begin{tabular}{lccccc} 
& Annual & DJF & MAM & JJA & SON \\
\hline mean $(k W)$ & 695.81 & 208.94 & 181.09 & 135.53 & 170.26 \\
$S D(k W)$ & 41.433 & 23.56 & 19.12 & 11.07 & 18.18 \\
$C_{v}$ & 0.06 & 0.11 & 0.11 & 0.08 & 0.11 \\
$L T_{100 y r}(\%)$ & -5.59 & - & -6.23 & -8.96 & -5.65 \\
periods (yrs) & 27 & - & 46 & - & - \\
\hline
\end{tabular}


Table 2

As Table 1 but for T2.

\begin{tabular}{lccccc} 
& Annual & DJF & MAM & JJA & SON \\
\hline mean $(k W)$ & 553.51 & 151.30 & 139.00 & 122.95 & 140.27 \\
$S D(k W)$ & 35.69 & 13.93 & 13.92 & 14.69 & 18.66 \\
$C_{v}$ & 0.06 & 0.09 & 0.10 & 0.12 & 0.13 \\
$L T_{100 y r}(\%)$ & 6.94 & 4.79 & - & 6.40 & 15.97 \\
periods (yrs) & 13,46 & - & 46 & 13 & 13 \\
\hline
\end{tabular}


Table 3

Statistics for the 1871-2009 annual series of the Weibull parameters derived of the obtained wind speed annual PDFs, for T1 and T2.

\begin{tabular}{lcccc} 
& \multicolumn{2}{c}{$T 1$} & \multicolumn{2}{c}{$T 2$} \\
\cline { 2 - 5 } & $k$ & $c$ & $k$ & $c$ \\
\hline mean & 2.37 & 9.51 & 1.67 & 8.16 \\
$C_{v}$ & 0.016 & 0.032 & 0.019 & 0.048 \\
Lin.trend (\%) & -2.31 & -2.51 & -1.56 & +5.01 \\
periods (yrs) & - & 13 & 27 & 13 \\
\hline
\end{tabular}




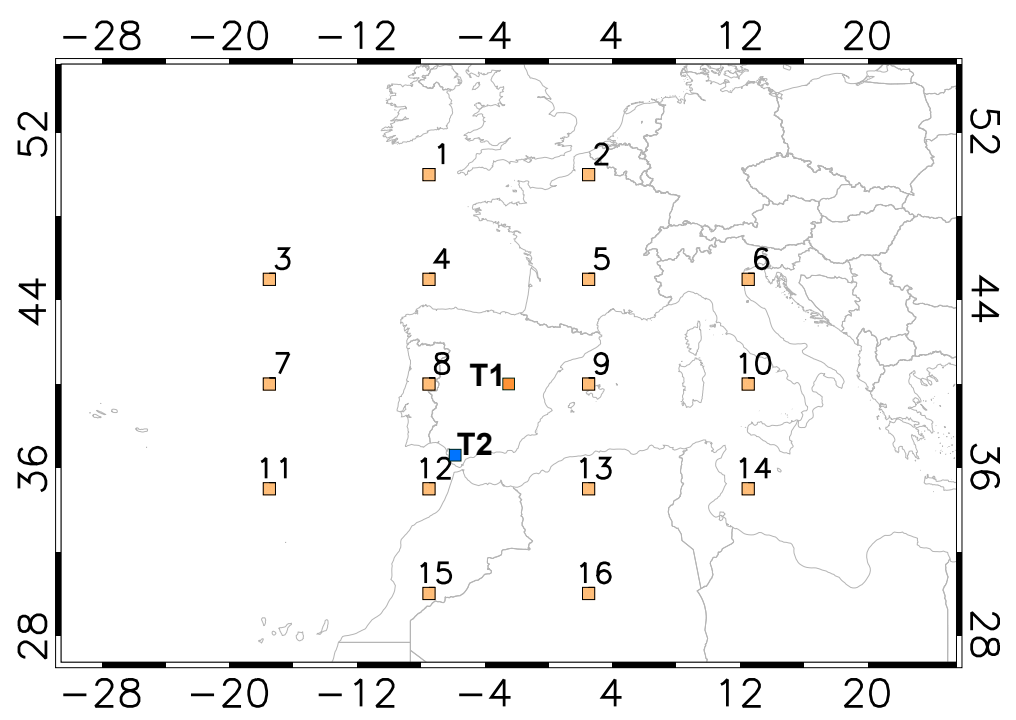

Fig. 1. Example of the considered SLP grid structure employed in the definition of the Wind Types at the introduced algorithms for T1. T2 is also depicted. 
F field

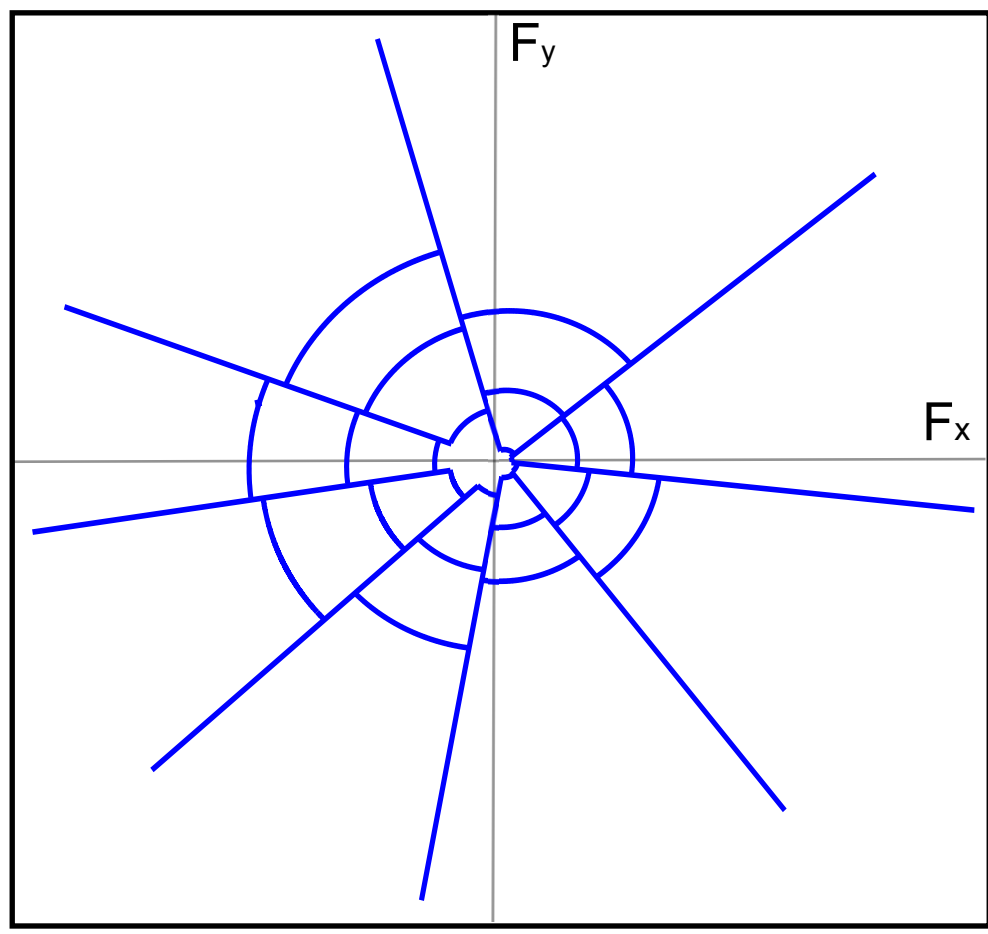

Fig. 2. Sample of a possible solution for the WT classificator. 


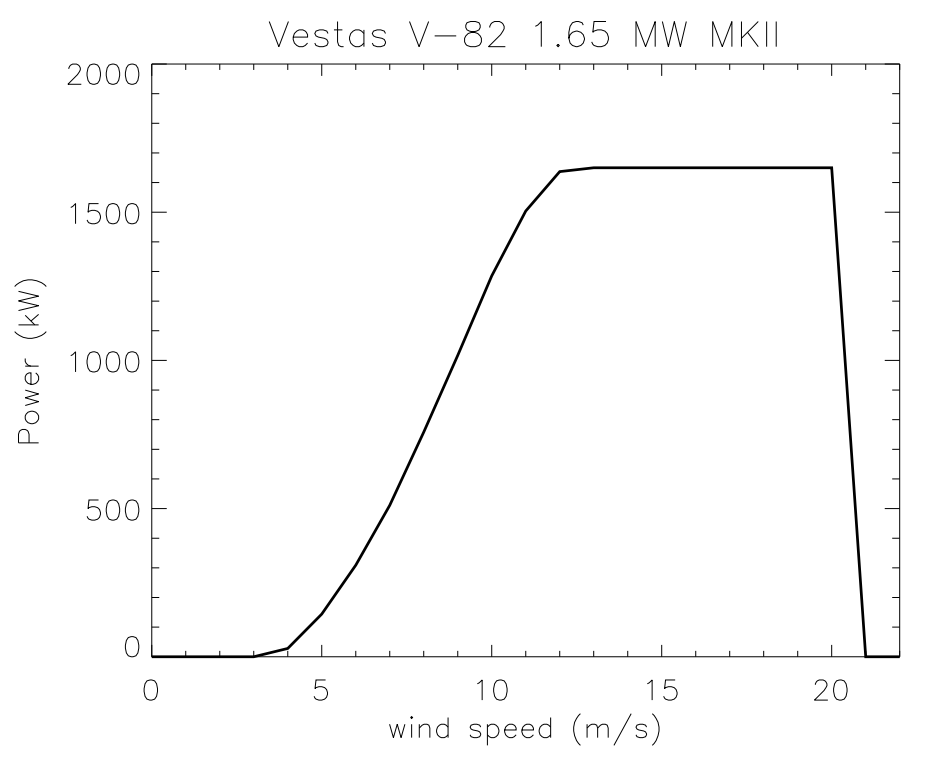

Fig. 3. Power Curve of wind turbine Vestas V-82 1.65 MW MK II for an air density of $1.225 \mathrm{~kg} / \mathrm{m}^{3}$. The minimum and maximum wind speeds for the turbine to operate are $3.5 \mathrm{~m} / \mathrm{s}$ (cut-in) and $20 \mathrm{~m} / \mathrm{s}$ (cut-out) respectively. 


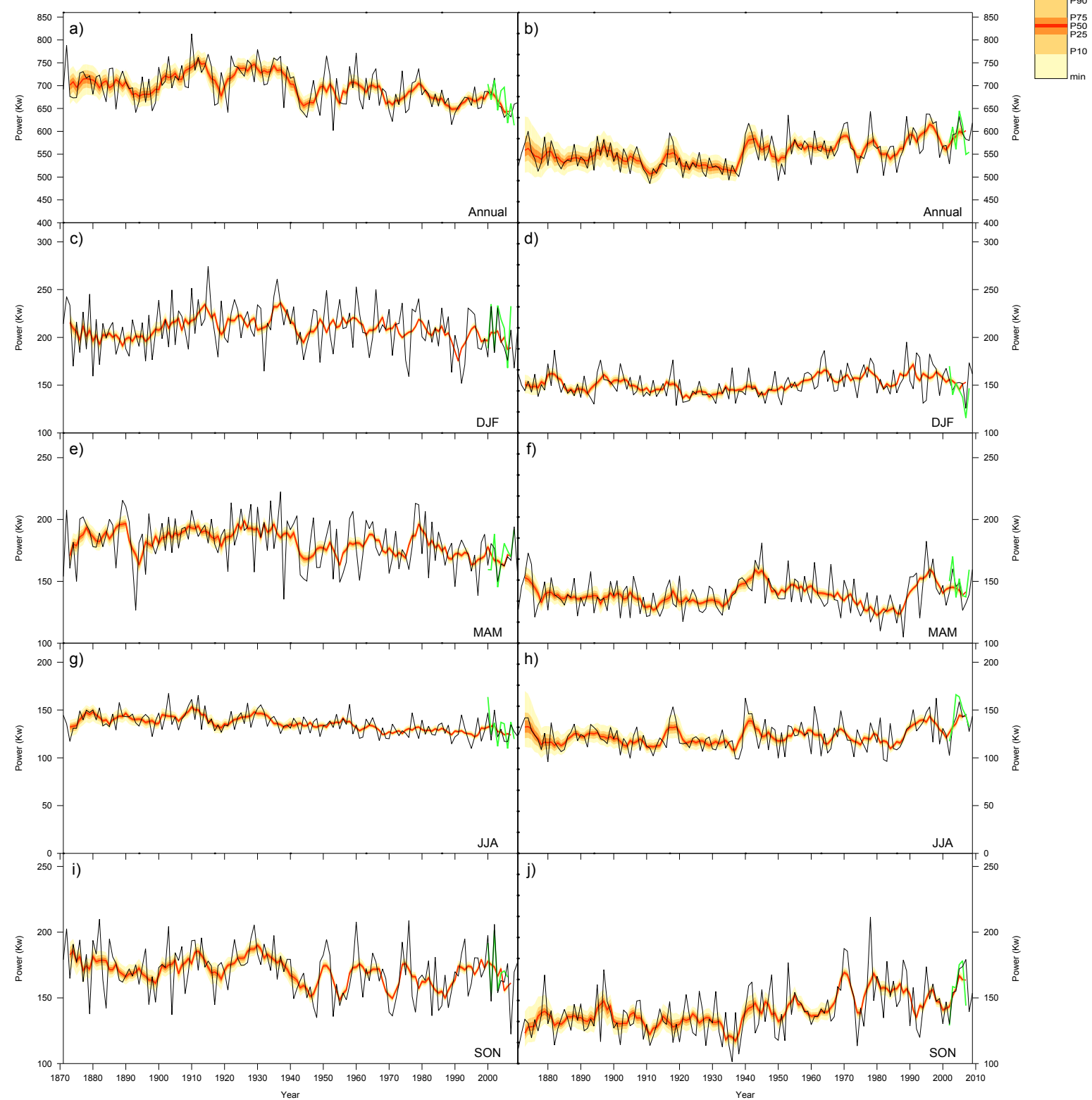

Fig. 4. Annual estimated $P_{o}$ (1871-2009) for the Vestas V-82 turbine at T1 and T2 sites. A-B describe the overall year-round signal, c-j stands for the seasonal series. The green line denotes the $P_{o}$ estimated strictly from observations. 

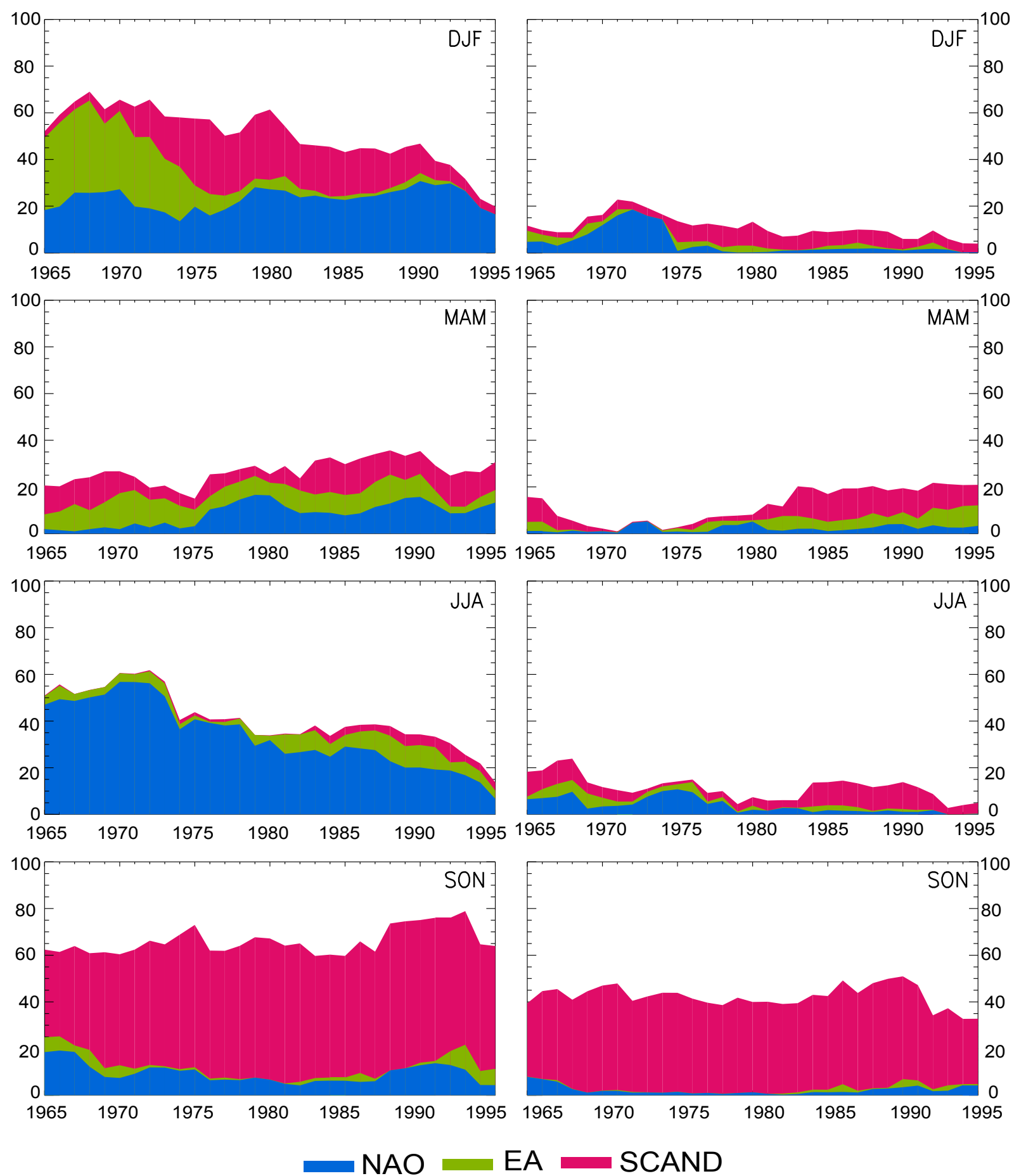

Fig. 5. Seasonal evolution of the explained variance $\left(r^{2}, \%\right)$ of Output Power at T1 (left) and T2 (right) by each one of the three principal variability modes of the North Atlantic-European region. Years refer to the 15 th year of a $30 \mathrm{yr}$ running correlation. 


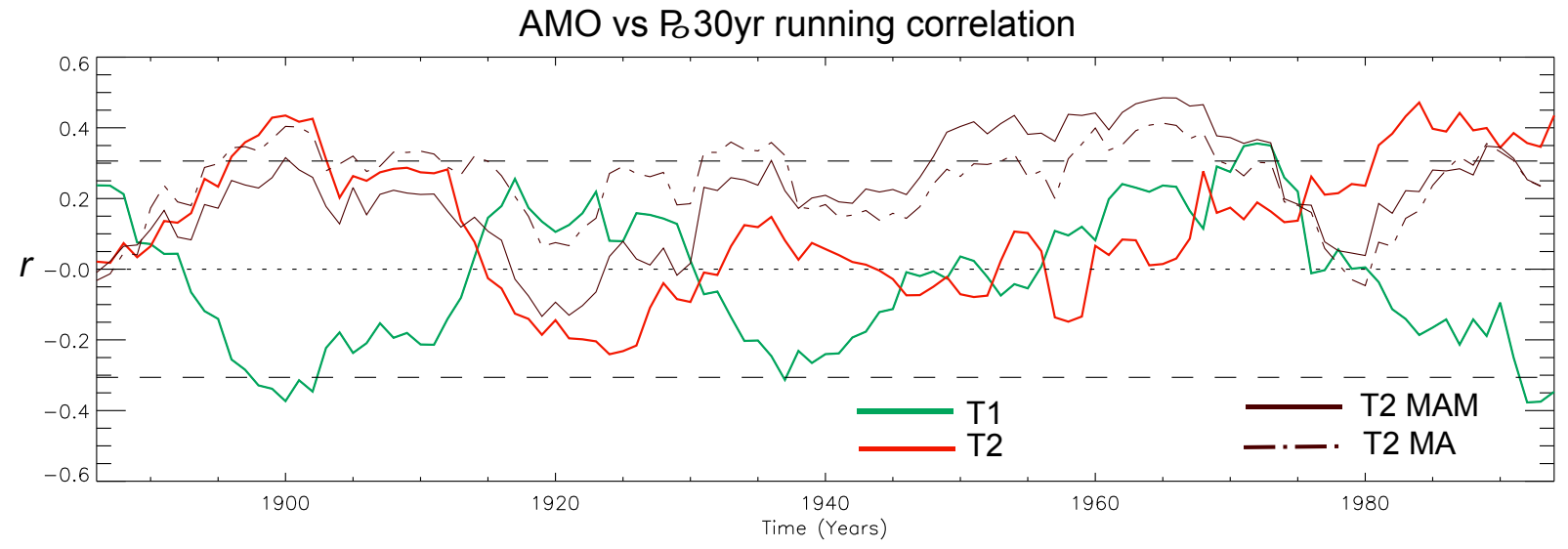

Fig. 6. 30yr running Pearson correlation coefficient between AMO index and the annual power output series. The horizontal axis indicates the center of every $30 \mathrm{yr}$ window considered. Dashed horizontal lines correspond to a $\mathrm{p}<(0.05)$ statistic significance level. 

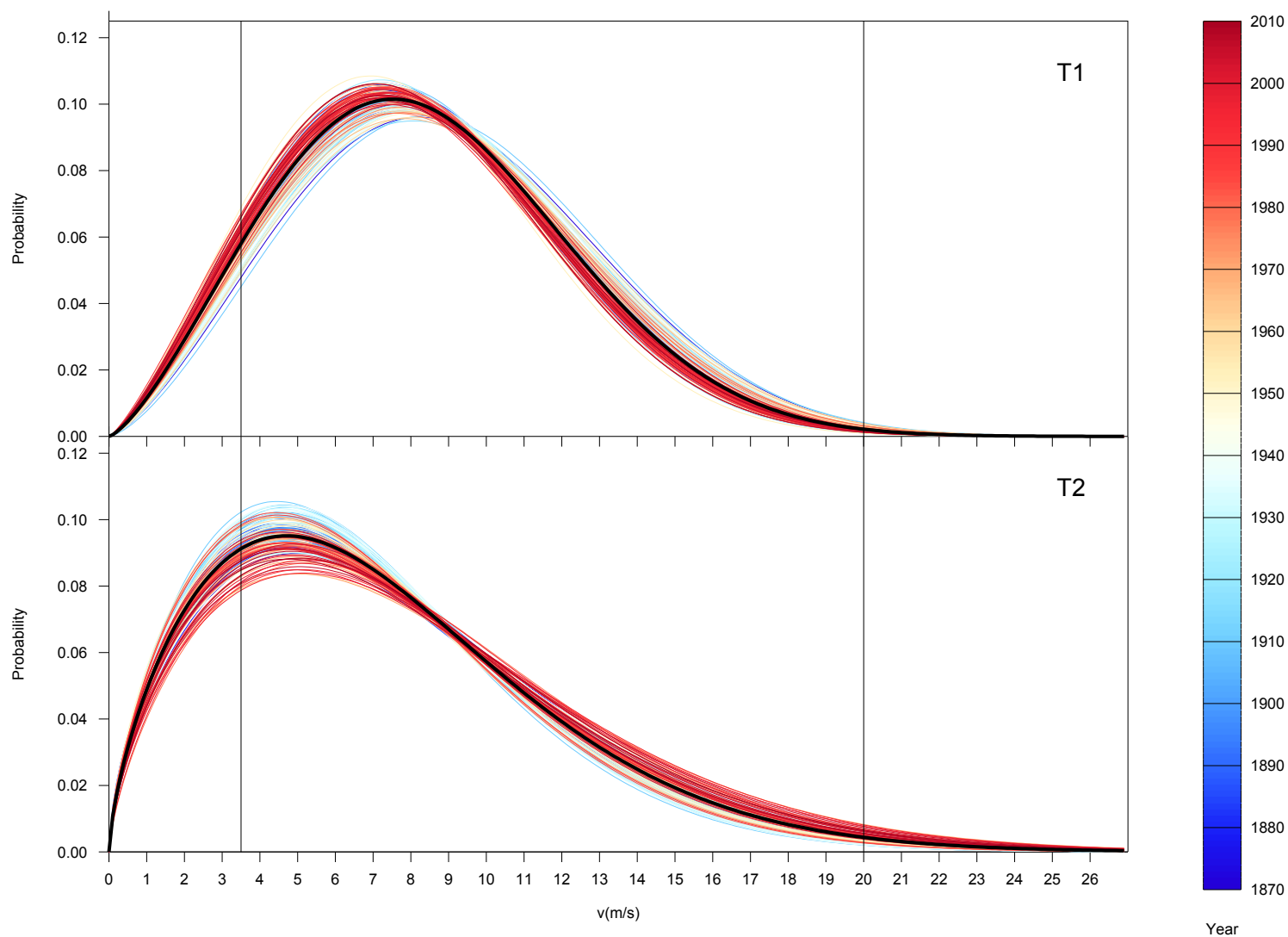

Fig. 7. Set of reconstructed annual Weibull probability density functions of the wind speed distribution at T1 (top) and T2 (bottom) for every year within the period 1871-2009. The year of the curve can be identified through the color scale (right). The black line represents the average climatological PDF. 


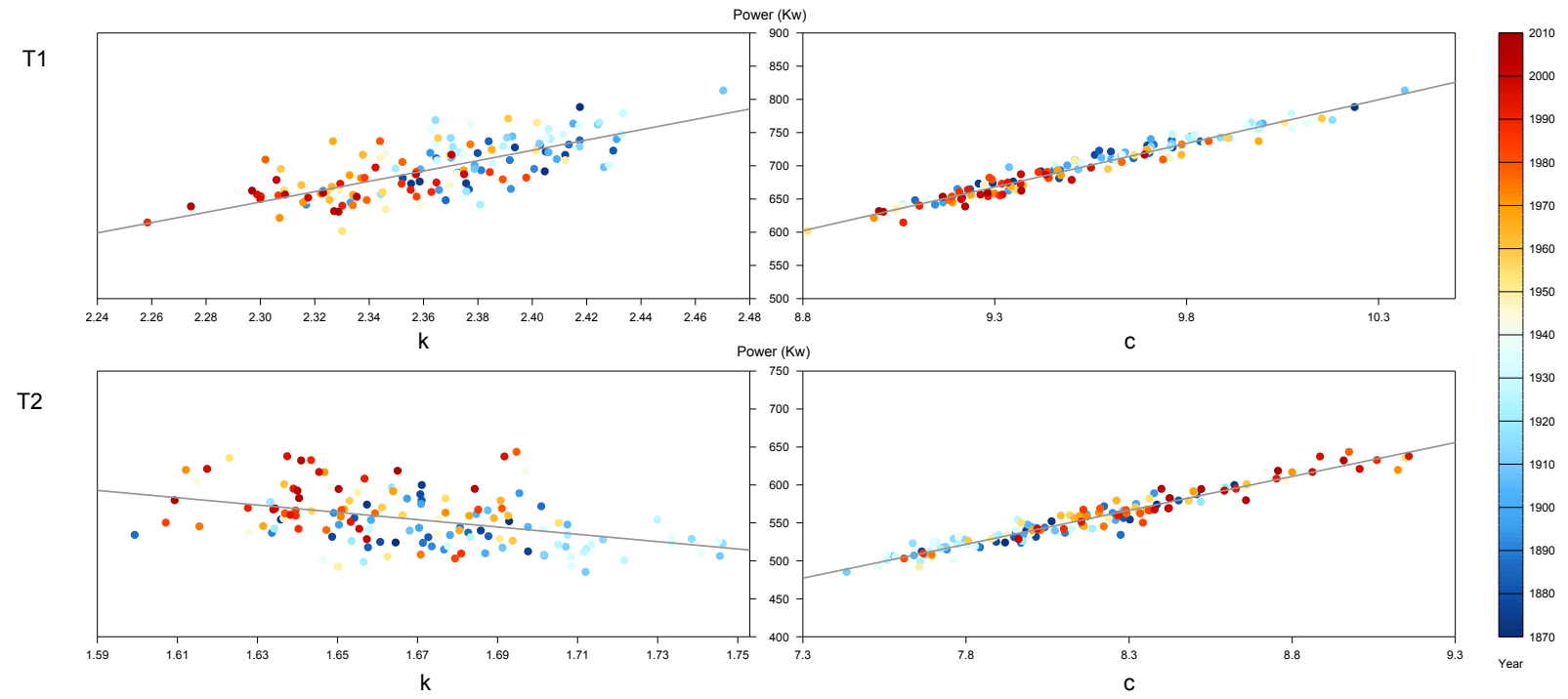

Fig. 8. Linear fitting for the ratio between the obtained annual Weibull paramenters $k$ (left) and $c$ (right) and the annual $P_{o}$, for tower T1 (up) and T2 (down). 